\title{
Co-Operative Air Traffic Management: Concept and Transition
}

\author{
Thomas Prevot ${ }^{*}$, Todd Callantine ${ }^{\dagger}$, Paul Lee ${ }^{\ddagger}$, Joey Mercer ${ }^{\S}$ \\ San Jose State University/NASA Ames Research Center, Moffett Field, CA, 94035 \\ Vernol Battiste $^{* *}$, Everett Palmer ${ }^{\dagger \dagger}$, Nancy Smith \\ NASA Ames Research Center, Moffett Field, CA, 94035
}

\begin{abstract}
Co-Operative Air Traffic Management (CO-ATM) is a concept under exploration at NASA Ames Research Center for transformation of aircraft and air traffic management operations towards the Next Generation Air Transportation System (NGATS). A goal of the CO-ATM concept is to provide a scalable framework to significantly increase NAS capacity and efficiency while maintaining safety. A second goal of this concept is to provide airspace users with increased flexibility in managing their operations. The concept aims at achieving substantial capacity and efficiency benefits through improved information exchange and changes in roles and responsibilities. It builds on lessons learned from Distributed Air/Ground Traffic Management (DAG-TM) research, and addresses identified safety, coordination, automation and mixed equipage concerns. CO-ATM provides a transition path from the current system to the next generation with gradual shifts in roles and responsibilities and incentives for aircraft operators to equip.
\end{abstract}

CO-ATM envisions sector controllers controlling conventional aircraft along predictable flight paths and area controllers coordinating strategic trajectory changes with flight crews of equipped aircraft in the same airspace via data link. Area controllers operate with extensive automation support for conflict detection and resolution and traffic flow management. Flight path changes are automatically shared as 4D trajectories between area and sector positions. Routine tasks like handoffs and transfer of communication are conducted by the automation. Equipped aircraft may be cleared to operate at different levels of autonomy. Tasks like aircraft-to-aircraft spacing may be delegated to the flight crews by the controller. Flight crews of equipped aircraft can coordinate preferred trajectories for traffic flow constraints with the area controller or operate at higher levels of autonomy, if desired and authorized.

The paper reviews plans and concepts for the NGATS and relevant research findings from DAG-TM studies. It introduces the CO-ATM concept in detail and presents a possible transition path in line with ongoing research at NASA Ames, addressing the integration of trajectory based operations and Airborne Separation Assistance Systems (ASAS). This concept is currently in its definition and exploration phase and is in line with research funded in the NextNAS project of NASA's Airspace Systems Program.

\footnotetext{
* Senior Research Engineer, Human Factors Research and Technology, NASA ARC, MS 262-4, AIAA member

${ }^{\dagger}$ Senior Research Engineer, Human Factors Research and Technology, NASA ARC, MS 262-4, AIAA member

* Research Psychologist, Human Factors Research and Technology, NASA ARC, MS 262-4

$\S$ Masters Student, Human Factors Research and Technology, NASA ARC, MS 262-4

${ }^{* *}$ Human Factors Engineer, Human Factors Research and Technology, NASA ARC, MS 262-

${ }^{\dagger}$ Human Factors Engineer, Human Factors Research and Technology, NASA ARC, MS 262-4

\# Research Psychologist, Human Factors Research and Technology, NASA ARC, MS 262-4 


\section{Nomenclature}

$\begin{array}{ll}A A C & =\text { Advanced Airspace Concept } \\ A D S-A / B & =\text { Automatic Dependent Surveillance-Addressed/Broadcast } \\ A O C & =\text { Airline Operational Control } \\ A S A S & =\text { Airborne Separation Assistance System } \\ A T M & =\text { Air Traffic Management } \\ A T S P & =\text { Air Traffic Service Providers } \\ C D \& R & =\text { Conflict Detection and Resolution } \\ C D T I & =\text { Cockpit Display of Traffic Information } \\ C O-A T M & =\text { Co-Operative Air Traffic Management } \\ C P D L C & =\text { Controller Pilot Data Link Communication } \\ C T A S & =\text { Center/TRACON Automation System } \\ D A G-T M & =\text { Distributed Air Ground traffic Management } \\ D S R & =\text { Display System Replacement (Center Controller Workstation in the NAS) } \\ D S T & =\text { Decision Support Tool } \\ E / D A & =\text { Enroute and Descent Advisor } \\ F A A & =\text { Federal Aviation Administration } \\ F D & =\text { Flight Deck } \\ F M S & =\text { Flight Management System } \\ M A C S & =\text { Multi Aircraft Control System } \\ N A S A & =\text { National Aeronautics and Space Administration } \\ T M A & =\text { Traffic Management Advisor } \\ T R A C O N & =\text { Terminal RADAR Approach Control } \\ R V S M & =\text { Reduced Vertical Separation Minima } \\ S T A R S & =\text { Standard Terminal Automation Replacement System (TRACON Controller Workstation in the NAS) }\end{array}$

\section{Introduction}

T n December 2004 the Joint Planning and Development Office (JPDO) transmitted the "Integrated National IPlan for the Next Generation Air Transportation System"1 to the United States Congress. The plan stresses the need for a new technology-enabled approach to air transportation. It outlines a high-level vision for 2025 that combines increased automation with new procedures to achieve economic, capacity, safety, environmental, and security benefits. The plan presents a number of operational concept elements that are aimed at tripling sector and airport capacity by 2025. New avionics will enable aircraft to operate with increasing levels of autonomy and increase flight deck situational awareness. Intelligent applications of automation will make new Air Traffic Management (ATM) concepts possible including shared or distributed separation management. ATM operations are envisioned to rely on end-to-end strategic traffic flow management, data link communication and information sharing to facilitate quiet and fuel efficient flight profiles coordinated between ground automation and airborne flight management systems while minimizing adverse weather effects.

The JPDO identifies 8 transformation strategies with key research areas. The research presented in this paper is in line with the applicable strategies and specifically addresses the first key research area for the strategy to Establish an Agile Air Traffic System: "Conduct research to evaluate alternative allocations of air traffic management services and functions between the ground and the air, and the automation and the human, to address critical system attributes such as capacity, agility, cost, human factors, reliability, safety, performance, and transition paths."

\section{A. Far-Term Concepts}

Visions for tripling capacity in 2025 rely on new automation and procedures to offload tasks from the air traffic controller. One approach is the concept of airborne self-separation (ASAS 4) , $^{2,3}$ that allocates air traffic control tasks including separation management to flight crews of appropriately equipped aircraft. Another approach is the advanced airspace system ${ }^{4}$ that focuses on the ground automation as the primary means for providing air traffic services with the air traffic controller in a supervisory role.

Both these approaches require a highly advanced Communication, Navigation and Surveillance (CNS) infrastructure to exchange 4D trajectories and advanced Decision Support Tools (DST) on the ground side and/or the aircraft for short and medium term conflict detection and resolution. Moreover, a substantial paradigm shift 
regarding the roles and responsibilities of flight crews, controllers and automation will be necessary to put these concepts into operation.

\section{B. Current Situation}

The current air traffic system, however, is far from ready to support any of these future visions, even though advanced CNS technologies and DSTs are operationally implemented and applications are defined to use these technologies.

Automatic Dependent Surveillance-Broadcast (ADS-B) and Controller Pilot Data Link Communication (CPDLC) are already used in local regions scattered around the world and are expected to be more widely used in the near future. On the ground side ADS-B can enable surveillance applications in areas with no radar coverage and enhance information for controllers and their decision support tools. On the flight deck ADS-B can enable flight crews to use traffic information for enhanced situation awareness and separation assistance tasks. Near-term applications of ADS-B are being defined and fast-tracked through ICAO and the authorities to make immediate use of this technology in the current day environment. Ground-based tools for strategic metering and flow management and airborne automation for more efficient flight path management are developed and implemented in addition to ADS-B and CPDLC enabled technologies.

The CO-ATM concept presented in this paper provides a framework for future air traffic operations enabled by advanced ground-based automation, ASAS and new CNS technologies. Moreover, it addresses how today's various modernization trends can be integrated and aligned along an incrementally beneficial transition path. In the following section we will review some of the research that motivated the development of the CO-ATM concept. Then we will explain the CO-ATM concept in detail.

\section{Motivation - Related Research}

Development of the CO-ATM concept is motivated by several factors. Firstly, our extensive recent research on Distributed Air/Ground Traffic Management (DAG-TM) concepts like airborne self-separation, airborne spacing and trajectory negotiation has provided us with more insights on potential capacity, efficiency and safety impacts of the various concept elements. Secondly, our ongoing research on a gradual transformation of the airspace system using Trajectory-Oriented Operations with Limited Delegation (TOOWiLD) indicates a promising approach to integrating the air and the ground systems on a conceptual, procedural and technological level. Thirdly, research on multi sector planning (MSP) and air/ground integration as well as current trends towards implementing early airborne separation assistance systems (ASAS) may provide a realistic avenue for transforming the airspace system. While TOOWiLD and MSP research are ongoing activities that are expected to produce preliminary results by mid 2006, the funded DAG-TM research has been completed. Some DAG-TM results are presented below to review particular aspects in developing the CO-ATM concept presented in section III of this paper.

\section{A. Distributed Air/Ground Traffic Management (DAG-TM) Overview}

NASA's Airspace Systems program and its Advanced Air Transportation Technologies project funded research on Distributed Air Ground Management (DAG-TM) between 2000 and 2004. DAG-TM is an integrated operational concept in which flight deck (FD) crews, air traffic service providers (ATSP) and aeronautical operational control (AOC) personnel use distributed decision-making to enable user preferences and increase system capacity, while meeting air traffic management (ATM) requirements. The DAG-TM concept was formulated as a coherent set of solutions to a series of key ATM problems (or inefficiencies) in the gate-to-gate operations of the current NAS. For each problem, one or more solutions were identified that could potentially solve the problem by utilizing distributed decision-making between the user (FD and/or AOC) and the ATSP. These solutions, known as concept elements (CEs), would potentially enable greater accommodation of user preferences and increased system capacity. A fundamental goal of the DAG-TM concept is the elimination of static restrictions, to the maximum extent possible. In this paradigm, users may plan and operate according to their preferences - as the rule rather than the exception with deviations occurring only as dynamically necessary. Therefore, fourteen DAG-TM concept elements were originally formulated to mitigate the extent and impact of dynamic NAS constraints, while maximizing the flexibility of airspace operations. ${ }^{3}$

Four of the fourteen concept elements were selected for thorough investigation. We -the authors of this paper were part of the core research team that investigated the following three concept elements: 
- Concept Element 5: Free Maneuvering for user-preferred separation assurance and local traffic flow management (TFM) conformance.

- Concept Element 6: Trajectory Negotiation for user-preferred separation assurance and local TFM conformance

- Concept Element 11: Self-spacing for merging and in-trail separation

The simulation results can be summarized as follows: The free maneuvering concept element (CE5) mixing operations with airborne self-separating and controller-managed aircraft demonstrated a tremendous potential for increasing capacity, if the separation responsibility within a given airspace is split among multiple operators. However, airborne self-separation has raised safety concerns and requires substantial new automation in the air and on the ground. ${ }^{5,6}$ The concept of trajectory negotiation (CE6) has been deemed a non-controversial concept for exchanging efficient 4D trajectories between the air and the ground and may provide substantial, but probably insufficient capacity increases if integrated into the current infrastructure ${ }^{7}$. Airborne spacing (CE11) has also been shown to be an acceptable and feasible concept; delegating well defined tasks to the flight crews. ${ }^{8,9,10,11}$

Excerpts of the gathered results are reviewed in the next sections; see the referenced DAG-TM reports for more complete experimental descriptions and analyses. ${ }^{5-9}$

\section{B. Free maneuvering: Mixed operations with airborne self-separation}

A Joint NASA Ames/Langley simulation of mixed operations was conducted in June 2004. ${ }^{5,6}$ During the simulation self-separating aircraft (also referred to as free maneuvering, or autonomous aircraft) shared en route and transition airspace with controller-managed aircraft. Flight crews of self separating aircraft had to separate themselves from all other traffic, while controllers were responsible for separating only the conventional aircraft from each other.

The analysis of aircraft counts and workload data across four sectors revealed that the sector controller's workload is primarily related to the number of aircraft he or she controls. Many more aircraft may be added to the same airspace if someone else is responsible for their separation. However, controllers reported that as the total number of aircraft increased, their available options for safely managing their traffic decreased. Figure $1^{6}$ visualizes the relationship between the number of controller-managed flights, self-separating aircraft and controller workload for different traffic mixes (Conditions 1-4). In Condition 1 (C1) controllers managed trajectories and separation for all aircraft. In C2-C4 traffic mixes with an increasing number of self separating aircraft were simulated. Workload was measured during the simulations using workload assessment keypads that prompted controllers to rate their workload on a scale of 1 (lowest) to 7 (highest) every five minutes.

In the current day environment the Monitor Alert Parameters (MAP) for these sectors are set such that controllers control less than 20 aircraft at all times. During the simulations with ground automation for handoff and communication changes controllers handled more traffic than today. The workload appeared to be primarily related to the number of managed aircraft in each sector which was held constant, and not to the total sector count which was up to $3 \mathrm{x}$ current day traffic levels.
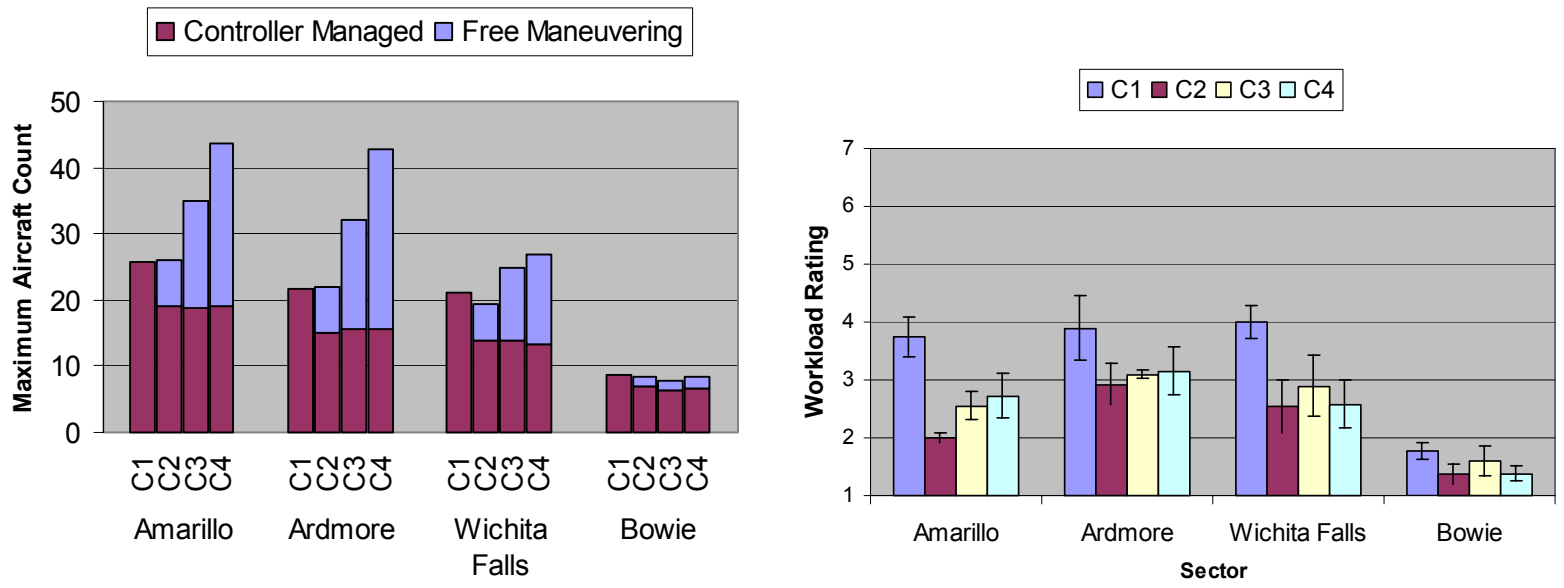

Figure 1: Maximum aircraft count and controller workload for 4 test sectors across 4 conditions (C1-C4) during DAG-TM simulations [6] 
The idea of air/ground distributed separation responsibility, however, has raised a number of safety concerns with the controllers - fueling sometimes passionate discussions about its acceptability and the required paradigm shift. The controllers' subjective safety ratings and comments reflect these concerns. Controllers rated mixed operations much less safe than managed operations ${ }^{5,6}$. However, this assessment was based on one particular concept implementation at an early technology readiness level. Therefore, these safety concerns should not be considered a show stopper for the concept of airborne self-separation, but they need to be taken very seriously. More research is required and significant adjustments to the concept of operations need to be made before mixed operations at the high traffic levels simulated during DAG-TM can be realized.

In addition to the safety concerns, airborne self-separation requires a highly developed infrastructure with extensive new air and ground equipage for self-separating and managed aircraft.

It is our opinion that equipping for airborne self-separation should be optional for aircraft operators rather than an ATM requirement to increase capacity. It is therefore desirable to create an environment that can achieve the capacity increase without requiring airborne self-separation. The system should however be designed in a way that autonomous aircraft operations can be authorized and operators can take advantage of the increased flexibility and efficiency provided by new airborne avionics systems.

\section{Trajectory Negotiation: Data linking trajectories between ground-based DSTs and the FMS}

The concept of trajectory negotiation was investigated in a number of studies including several simulations at NASA Ames Research Center. Frequently the notion of trajectory negotiation refers to a multi-stage process including requests, responses and potential modifications to trajectories. We take a broader view to the concept. By trajectory negotiation we mean the data link exchange of trajectories between the flight deck and the ground-side automation. Simple cases are downlinking the active aircraft trajectory from the FMS to the ground automation or uplinking a trajectory clearance from the controller workstation to the flight deck. The next level of negotiation is a route request initiated by the flight crew that is reviewed by the controller and responded to via data link. Negotiations designed to consist of several phases of requests and modifications were discussed with pilots and controllers, but were not considered to be necessary and therefore not included in any of the studies conducted at Ames.

Experiments on air/ground integration between 1997 and 2000 identified the feasibility and benefits of data linking trajectories from the ground automation into the FMS ${ }^{12,13,14,15}$. DAG-TM research also made trajectory negotiation a central concept element. Two complimentary DAG-TM studies in 2002 and 2004 evaluated firstly the capacity and efficiency benefits of uplinking FMS loadable clearances from the controller to the flight deck and secondly the feasibility of flight crew initiated trajectory requests. Prevot et al. ${ }^{16}$ reported reduced arrival spacing variability, increased flight efficiency and positive controller workload impacts. Lee et al. ${ }^{17}$ documented the feasibility of downlink requests and trends in favor of data linking requests as opposed to voice requests.

The controller and flight crew interfaces underwent many improvements during the process. At the final DAGTM simulations in 2004 the controller and pilot tools for modifying, evaluating and data link trajectory modifications were seamlessly integrated with their workstations. Controllers and pilots preferred the concept of data linking trial planned trajectory changes between the ground and the air clearly over current day operations. Table $1^{18}$ summarizes some of the feedback of full performance level controllers gathered in post simulation questionnaires after the controllers had used a prototype DSR system that integrated CPDLC with advanced DSTs.

Clearly controllers were in favor of the advanced operations combining trajectory modifications with data link and trial planning tools. Details on the provided ground automation can be found in ${ }^{19}$. With this toolset and full aircraft equipage, vectoring was practically eliminated ${ }^{20}$ and almost all flight path changes were conducted via trajectory modifications. It should be noted that this process of management by trajectory is also a central component of enabling mixed autonomous/managed operations. This concept allows aircraft to stay on trajectories almost exclusively, which makes them more predictable than if they were vectored. As a result airborne conflict detection and resolution (CD\&R) logic can support flight crews more effectively, because the surrounding traffic (managed and self separating) provides stable trajectory intent information - a primary requirement for strategic CD\&R. 
Table 1: Controller responses to comparing trajectory-based clearances with CPDLC to current day operations

\begin{tabular}{|l|l|l|r|r|r|r|r|}
\hline \multicolumn{1}{|c|}{ Question } & \multicolumn{1}{|c|}{ Range } & $\begin{array}{l}\text { Low } \\
\text { Altitude }\end{array}$ & $\begin{array}{l}\text { High } \\
\text { Altitude } \\
\# 1\end{array}$ & $\begin{array}{l}\text { High } \\
\text { Altitude } \\
\# 2\end{array}$ & En route & Average \\
\hline 1 & $\begin{array}{l}\text { How useful was the ability to } \\
\text { obtain speed advisories when } \\
\text { trying to deliver aircraft to a } \\
\text { meter fix STA? }\end{array}$ & $\begin{array}{l}\text { extremely useful (5) } \\
\text { not very useful (1) }\end{array}$ & 5 & 5 & 5 & N/A & 5 \\
\hline 2 & $\begin{array}{l}\text { What impact do you think } \\
\text { the ability to datalink } \\
\text { clearances had on your } \\
\text { overall workload? }\end{array}$ & $\begin{array}{l}\text { greatly reduced (5) } \\
\text { greatly increased (1) }\end{array}$ & 5 & 5 & N/A & 4.67 \\
\hline 3 & $\begin{array}{l}\text { How effective were cruise } \\
\text { and descent speed clearances } \\
\text { for controlling arrival traffic } \\
\text { compared to current } \\
\text { operations? }\end{array}$ & $\begin{array}{l}\text { much more effective (5) } \\
\text { much less effective (1) }\end{array}$ & 4 & 5 & 4.5 & N/A & 4.5 \\
\hline 4 & $\begin{array}{l}\text { How effective were trial plan } \\
\text { route amendments compared } \\
\text { to vectoring used in current } \\
\text { day operations? }\end{array}$ & $\begin{array}{l}\text { much more effective (5) } \\
\text { much less effective (1) }\end{array}$ & 5 & 5 & 5 & 4 & 4.75 \\
\hline 5 & $\begin{array}{l}\text { How effective were trial plan } \\
\text { altitude amendments } \\
\text { compared to current day } \\
\text { operations? }\end{array}$ & $\begin{array}{l}\text { much more effective (5) } \\
\text { much less effective (1) }\end{array}$ & 3 & 5 & 5 & 4 & 4.25 \\
\hline 6 & $\begin{array}{l}\text { How useful was the ability to } \\
\text { datalink clearances compared } \\
\text { to voice clearances? }\end{array}$ & $\begin{array}{l}\text { much more useful (5) } \\
\text { much less useful (1) }\end{array}$ & 5 & 5 & 5 & 5 & 5 \\
\hline
\end{tabular}

Some findings have been very consistent throughout our trajectory negotiation research

- Uplinking FMS loadable trajectory clearances and downlinking the active FMS trajectory is desirable and beneficial and can improve delivery accuracy, predictability and eliminate excessive vectoring.

- Trajectory negotiation can be a simple process. Pilots and controllers had no problems with a simple task sequence that consisted of a request and a yes/no response. There is no evidence that a multi stage process is required. Therefore an initial implementation in the ground-based and airborne systems can be straightforward and still very powerful.

- It is very important that trajectory tools and data link is very responsive and properly integrated with the operator station to make the concept usable and useful in high traffic situations ${ }^{20}$.

Based on the positive results trajectory management/negotiation should be a central component of any future airspace architecture. The ongoing work on Tailored Arrivals ${ }^{21}$ is an important initial step into this direction by implementing trajectory exchange between the airborne FMS and the ground-based automation in the near term in a low density environment. In order to implement trajectory management effectively in high density airspace, controller and flight deck tools need to be well designed and integrated into their respective operator stations $\mathrm{s}^{20,22}$.

\section{Airborne Spacing}

Airborne spacing has also been evaluated in simulations in a number of studies ${ }^{7,8,9}$. In this concept controllers can assign flight crews of properly equipped aircraft a lead aircraft and an interval specified in time or distance to maintain to this lead aircraft using ADS-B and airborne spacing tools. Airborne spacing does not change responsibilities but increases the role of the flight crew in the spacing task. Controllers -as today- remain responsible for safe separation between aircraft. The general consensus derived from the conducted studies is that airborne spacing is acceptable to pilots and controllers if proper procedures and spacing algorithms are in place. It can increase controller availability and relieve controllers from some monitoring and tactical control tasks. One of 
the primary advantages of airborne spacing is its ability to increase the precision of inter-arrival spacing between aircraft.

A DAG-TM study at NASA Ames Research Center investigated terminal area FMS arrivals with airborne spacing and merging. In the study two professional terminal area controller pairs interacted with 9 commercial pilots and additional confederate controllers and pseudo pilots to evaluate four different conditions:

- Air Tools' - seventy-five percent of aircraft assigned to the primary landing runway were equipped for airborne spacing and controllers could issue self-spacing commands,

- 'Air and Ground Tools' - controllers also had DSTs available to aid in issuing airborne spacing clearances and monitoring conformance,

- 'Ground Tools' - controllers had DSTs available, but no aircraft were equipped for airborne spacing;

- 'No Tools' — basic FMS TRACON operations;

The increased precision of airborne spacing is documented in the spacing error at the final approach fix. Figure 2 shows the spacing accuracy at the final approach fix to the primary landing runway for that study ${ }^{7}$.

\section{Reference Point: FF18R}

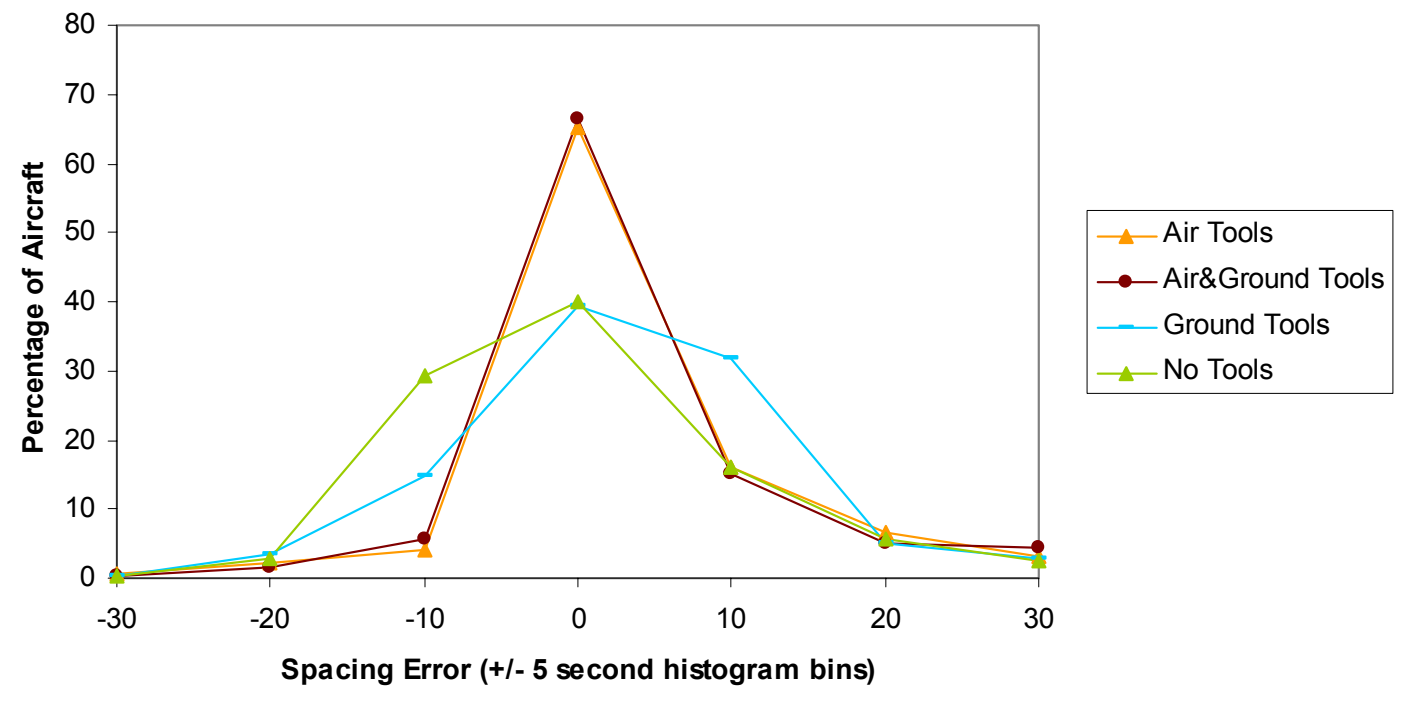

Figure 2: Spacing accuracy histogram measured at the Final Approach Fix during DAG-TM study conducted in 2004 at NASA Ames Research Center ${ }^{7}$

The results show that accuracy improves when aircraft are capable of airborne spacing in conditions 'with air tools.' The addition of controller DSTs in the Air and Ground Tools condition does not improve spacing accuracy beyond that obtained in the Air Tools condition. Ground Tools did, however, help controllers err on the conservative side relative to No Tools, suggesting an improved awareness of the required spacing that may help minimize goarounds. While workload always remained within an acceptable range, clearance data indicate that airborne spacing works best when linked to en route concepts capable of delivering aircraft in coordinated flows.

The concept of airborne spacing has recently gained significant momentum. The US/European Requirements Focus Group is tasked to establish application definitions, safety and performance analyses, and interoperability requirements for airborne spacing in order to prepare a widespread implementation. Airborne spacing should be considered a powerful tool for future air traffic management that can be applied to all phases of flight and requires only moderate equipage upgrades on the flight deck and the ground-side.

\section{E. Implications for future concepts}

The DAG-TM research has given us good insights into the potential benefits and problems of different concept elements. Our assessment can be summarized as follows: Trajectory management integrated with data link should be the standard mode of operation in the future system. Airborne spacing is a powerful tool for improving spacing accuracy. Airborne self-separation has good potential, but requires additional research and further refinements to 
determine whether it will be safely usable in congested airspace. DAG-TM investigated these concept elements primarily as non-integrated components. Variations of these concept elements have become integral parts of the concept of Co-operative Air Traffic Management, described in the next section.

\section{Co-Operative Air Traffic Management}

The concept of CO-ATM is designed to achieve capacity and efficiency benefits which will accrue from a distribution of roles and responsibilities and intelligent applications of automation while preserving current levels of safety in a mixed equipage environment. Furthermore, it is intended to provide incentives and benefits for equipped aircraft. CO-ATM is our approach to combine the beneficial properties of distributed separation responsibilities, trajectory negotiation, increased aircraft autonomy and automation assisted separation assurance.

The following sections describe the principles for co-operation and the air/ground infrastructure that is needed to enable CO-ATM operations. Then, CO-ATM ground-side and flight deck operations will be described.

\section{A. Principles for Co-operation}

The CO-ATM concept relies on co-operation between traffic management, controllers and flight crews for managing the increased traffic demand. The envisioned air traffic system combines time-based traffic flow management (TFM), absolute 4D trajectory-based operations and relative airborne spacing applications based on the temporal and spatial scope of the problem. This is in line with research findings and analyses of the air traffic system conducted in Europe and the US proposing the combination of absolute and relative operations $\mathrm{s}^{23,24}$.

The principles for applying TFM, 4D, and airborne spacing can be formulated as follows ${ }^{24}$ :

Use time-based flow management to regulate traffic density,

Use trajectory-based operations to create efficient, nominally conflict-free trajectories that conform to traffic management constraints and,

Maintain local spacing between aircraft with airborne separation assistance.

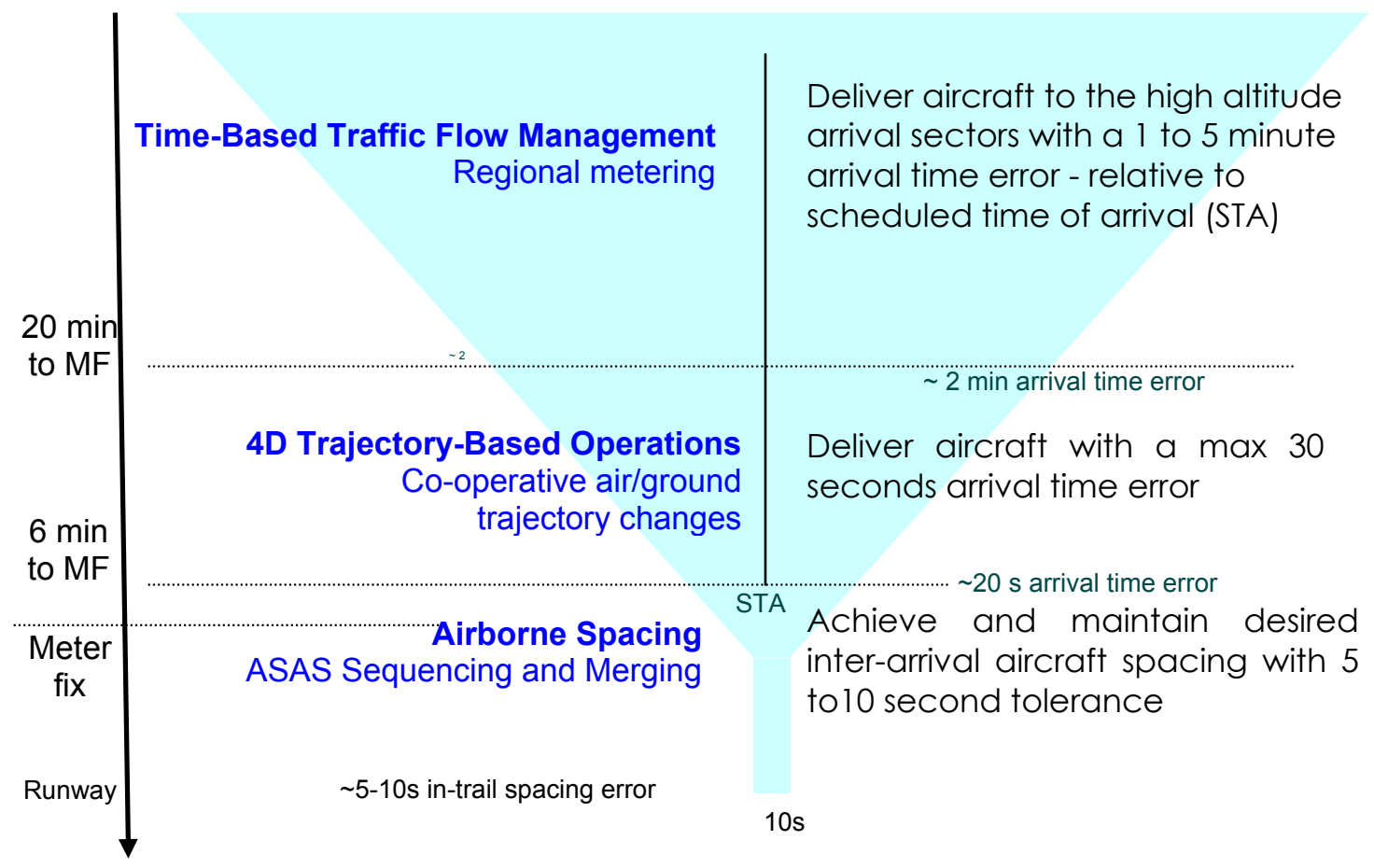

Figure 3: Example time horizons for co-operation between TFM, controllers and flight crews

Figure 3 indicates some example time horizons for co-operation between the different entities. Time-based TFM co-operates with airlines for scheduling purposes and to make sure that aircraft arrive at the appropriate time (within a few minutes) at the destination airports arrival sectors. Controllers co-operate with flight crews to further adjust aircraft trajectories so that aircraft can arrive at merge points for their approach routing with only small arrival time 
errors (e.g. less than 20 seconds). If the aircraft are properly set up for the merge controllers can delegate the task of fine-tuning the inter arrival spacing to the flight crews using airborne spacing procedures.

\section{B. Integrated Air Ground System Technologies}

The CO-ATM concept proposes to move the primary mode of interaction between controllers and flight crews of equipped aircraft from voice to data link. Frequent single task instructions from the controllers to the flight crews are replaced with infrequent trajectory adjustments or spacing clearances. In order to accomplish this trajectory management task effectively controllers and the ground automation need to be informed about the current strategic flight intent and preferences of the aircraft. The integrated air/ground system is explained in detail in ${ }^{24}$ and ${ }^{25}$. The proposed technologies for the integrated air/ground system are:

- Air traffic service providers equipped with decision support tools for scheduling and trajectory planning.

- $\quad$ Aircraft equipped with flight management system (FMS)

- Addressed data link communication between ground-based decision support tools and FMS to exchange strategic information and routine messages between controllers and pilots

- ADS-B to provide state and short term-intent information to the ground and other aircraft

- ASAS and cockpit displays of traffic information (CDTI) on the flight deck with trajectory planning tools

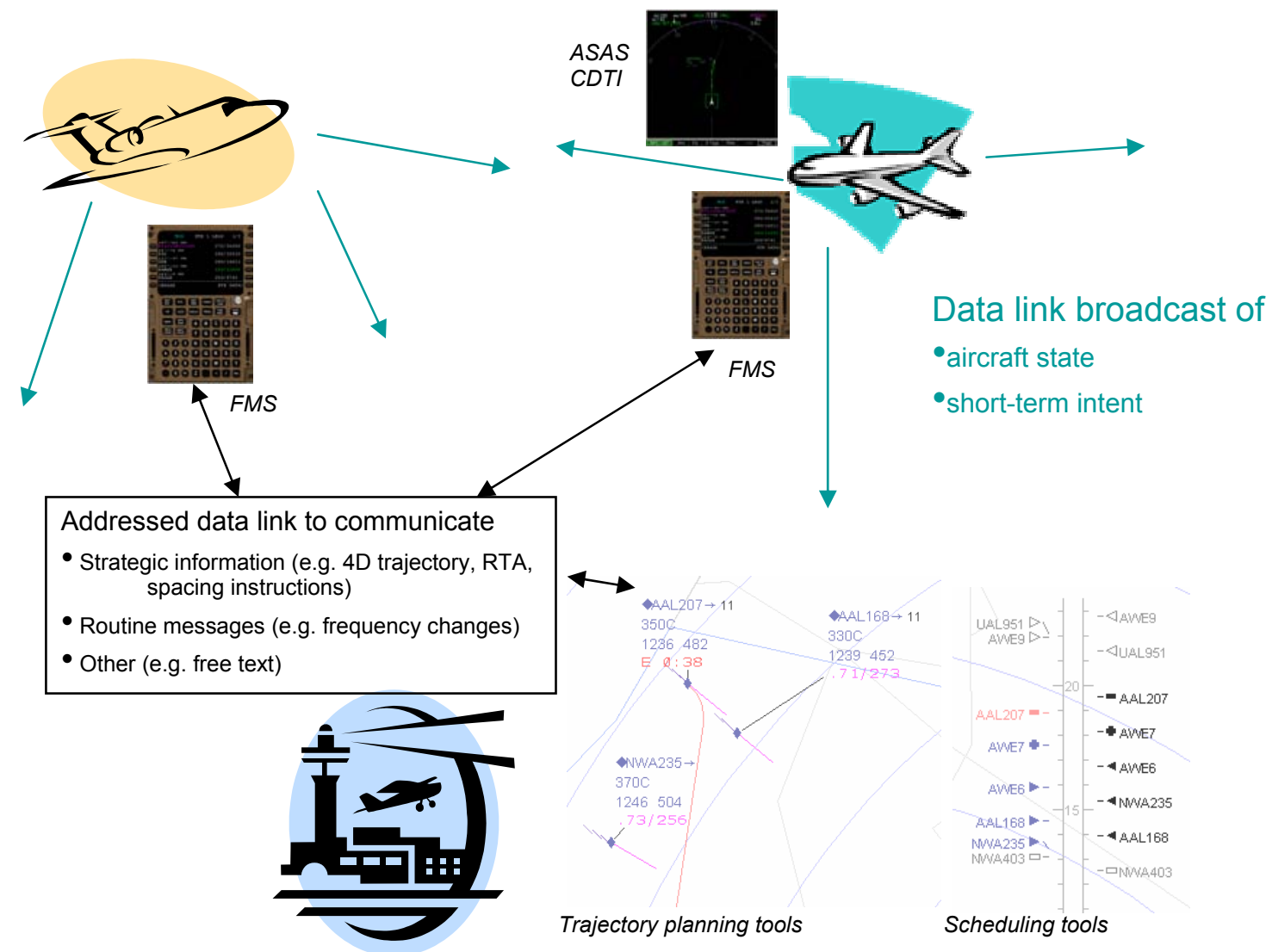

\section{Figure 4: Integrated Air/Ground System}

These technologies enable fully integrated co-operative air/ground operations. It is unrealistic to assume that all aircraft and all air traffic service providers will be equipped according to the standard above. Furthermore, the additional automation cannot be turned on overnight, thus changing the roles and responsibilities of all operators without gradually gaining operational experience. Therefore CO-ATM is designed to phase in new technologies, without directly affecting standard operations. However, it is intended to provide aircraft operators who decide to equip their aircraft early with immediate benefits. 

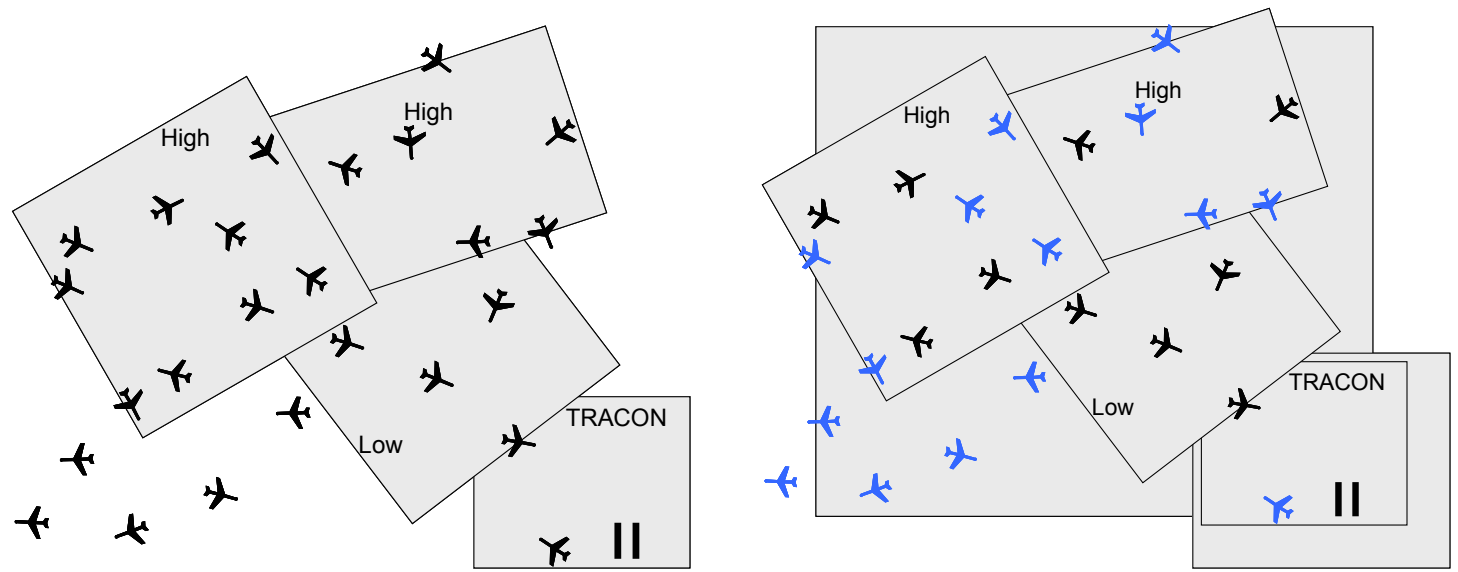

Figure 5.In the current system (left) all aircraft within a given sector are controlled by a single sector controller team. In CO-ATM (right) area controllers manage equipped aircraft and sector controllers control conventional aircraft in the same airspace.

\section{Ground-side Operations}

The DAG-TM research has highlighted that one avenue to increasing capacity significantly (2 to 3 times) is to distribute the responsibility for separation of aircraft in a given airspace among multiple operators. The basic idea of CO-ATM is to split the responsibility for managing air traffic between sector controllers and area flow controllers based on aircraft equipage. Sector controllers control "conventional" aircraft within their sector primarily via voice. Area controllers manage traffic flows of "equipped" aircraft via data link. "Equipped" aircraft have as a minimum FMS integrated CNS technologies. CPDLC and trajectory exchange capabilities -uplink and downlink- as well as ADS-B-out will be required for trajectory prediction accuracy. Traffic displays and airborne spacing capabilities will likely be necessary as the number of equipped aircraft increases. These tools will allow the controller to delegate spacing responsibility to the pilot at capacity constrained areas.

The area controllers operate on new multi sector positions that provide extensive automation support to the controller for conflict detection and resolution with traffic constraints. . The idea is that the area controllers will be able to include sector specifics into the strategic trajectory negotiation and conflict resolution process and thus reduce the number of conflicts encountered by individual sector controllers. Routine tasks like handoffs and transfer of communication are conducted by the automation on the area positions.

Figure 5 depicts a generic example about the re-assignment of air traffic from the current day system to a cooperative system. The sector organization remains basically unchanged as long as the number of conventional aircraft is sufficiently high to warrant today's sector distribution. While the sector controllers use voice for most clearances and CPDLC for some functions, the area controllers use CPDLC as the primary means of communication. Flight crews of equipped aircraft monitor the area controllers' frequency and are cleared to fly coupled to their FMS along the downlinked trajectory by default. Trajectory changes are coordinated with the area controllers unless autonomous operations have been authorized.

The ground system maintains accurate $4 \mathrm{D}$ trajectory predictions for all aircraft based on the best information available. The ground automation monitors these trajectories and the aircraft progress for compliance (security/safety) and conflicts (safety). Identified conflicts are highlighted to the responsible controller. For avoiding and resolving conflicts involving equipped and conventional aircraft, rules have to be defined governing the responsibilities. Near traffic bottlenecks, workload intensive tasks such as the fine-tuning of relative aircraft positioning can be assigned to the flight deck at the discretion of both area and sector controllers.

\section{Traffic management and coordination}

Increased use of time-based traffic flow management (TFM) is assumed in most far term ATM concepts including CO-ATM. Time-based TFM enables strategic trajectory planning and makes sure that traffic densities remain manageable.

A key requirement for CO-ATM is high flight path predictability. Current day flight path predictions in the ground system are based on filed flight plans with amendments. These descriptions can become obsolete or incorrect 
in high density situations, in which controllers' have to vector aircraft off their flight plans. The resulting flight path uncertainty has a negative impact on the strategic traffic scheduling process. Additionally, coordination across sector boundaries has to be done explicitly on a case by case basis.

In order to improve the strategic scheduling process and to avoid extensive explicit coordination, precise 4D trajectory descriptions based on FMS routes will replace the flight plan description in the envisioned ground system. Thus, sector and area controllers, traffic managers, and the ground and air side automation share a common understanding of each aircrafts trajectory. These trajectories need to accurately reflect the actual aircrafts' flight path to be meaningful. This can be achieved by utilizing the aircrafts FMS path generation and tracking capabilities. Equipped aircraft exchange trajectories between the FMS and the ground automation via data link. For conventional aircraft flexible FMS compatible procedures are used.

\section{Sector Controller Operations}

In the CO-ATM concept sector controllers are responsible for controlling the conventional aircraft within a given sector. Conventional aircraft are handed to sector controllers manually or by automatic handoff functions as today. Track control over equipped aircraft is only transferred to sector controllers manually or if no separate area controller position is used.

Equipped aircraft are displayed with minimum information unless pointed out by other controllers or the automation. This is consistent with today's handling of aircraft controlled by adjacent sector controllers.
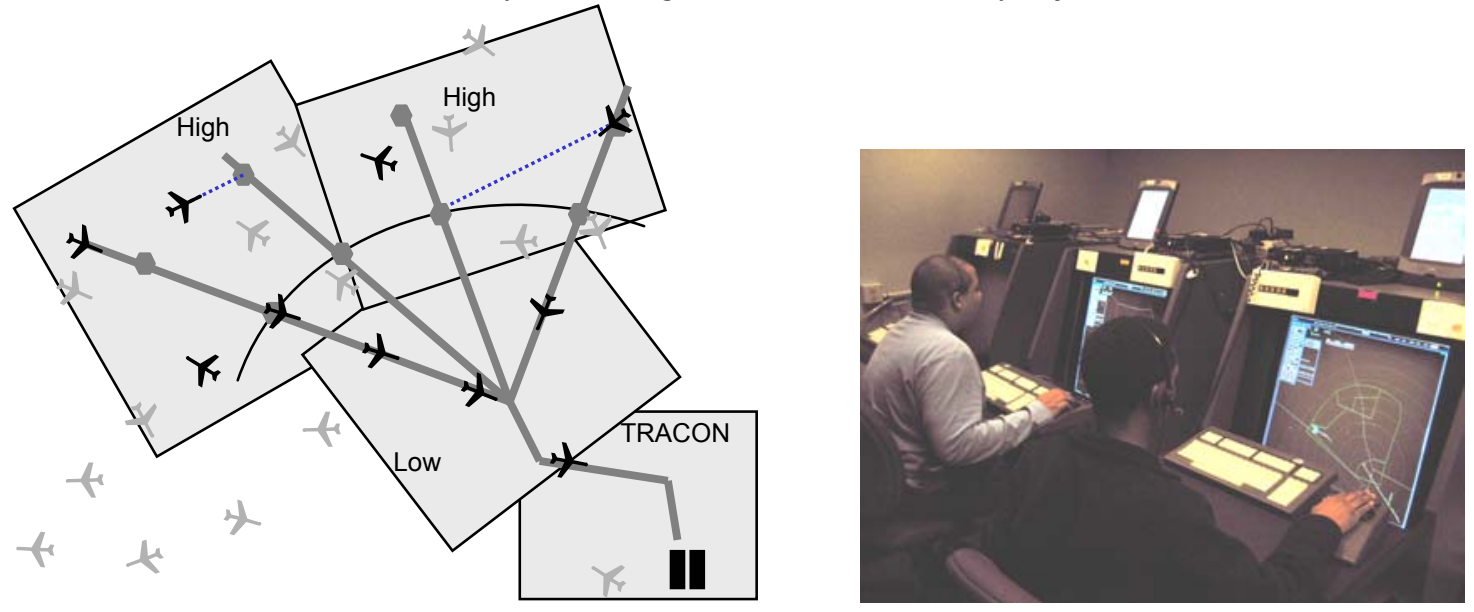

Figure 6: Sector controllers handle conventional aircraft along FMS compatible flight paths.

To increase flight path predictability sector controllers should use FMS compatible procedures whenever possible. Figure 6 indicates an example for an airspace structure that allows controllers to direct aircraft along predefined waypoints and routes to a merge point which could reduce vectoring. These modifications can be communicated to the flight crew by voice and entered into the ground system as flight plan amendment. Thus, the ground-based trajectory prediction can be well aligned with the aircrafts intent. DSTs are needed to support sector controllers in conflict probing and implementing appropriate route, speed and altitude amendments.

\section{Area Controller Operations}

Traffic flows of equipped aircraft are managed by area controllers with intelligent automation using CPDLC. The area position is a new multi-sector position that is designed to relieve controllers from all routine and tactical tasks. The ground-based automation initiates and accepts transfer of control and communication from and to adjacent sectors unless the controller intervenes. The automation also monitors all aircraft trajectories for TFM compliance and conflicts, and alerts the controller about necessary adjustments.

Trial planning and conflict resolution tools support the controller in determining necessary trajectory adjustments. Flight crews can request preferred trajectories at any time. The downlinked trajectories are checked by the ground system for conflicts and traffic flow compliance to support the controller in determining whether a trajectory change can be approved. When the system achieves some level of equipage where data is available of all aircraft the flight deck system will submit conflict free trajectory change request. 

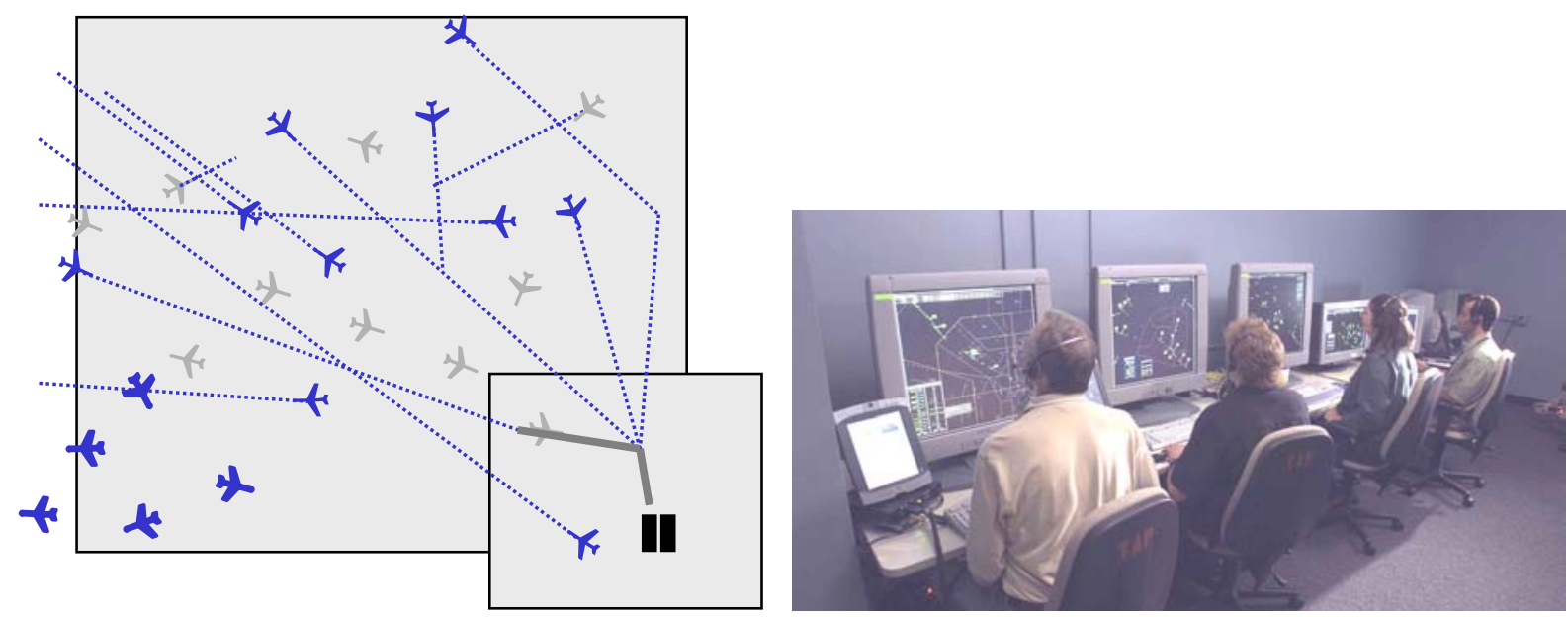

Figure 7: Area controllers handle equipped aircraft with automation support along their most efficient route via data link

Flight crews of equipped aircraft monitor the area controllers' frequency. However during normal operations no radio communication should be required between the flight crew and the controller. Cockpit displays of traffic information are used to maintain flight crew traffic awareness, replacing today's party-line information. Airborne spacing can be assigned by the area controllers for station keeping and sequencing and merging tasks. If so desired area controllers can authorize higher levels of autonomy like limited delegation of authority for separation between aircrafts pairs or full airborne self-separation. All operations will be monitored by the ground automation for security and safety as well as TFM compliance. The area controller can assist self-separating flight crews in airspace management and conflict resolution, if requested.

If the ground automation, the flight crew, or the area controller detects a conflict or a problem that cannot be resolved with a trajectory change, the area controllers have several options depending on the situation. They can task the flight crew to maintain spacing. They can use voice communication to provide an immediate instruction to the flight crew. They can co-ordinate with the sector controller and hand-off track control and communication to let the sector controller handle the aircraft.

\section{Flight Deck Operations}

Co-ATM provides a framework for airspace users to choose the type of flight operations and the associated equipage based on their requirements and/or business models within certain limitations. Operators who decide not to invest in new equipage can still use the airspace, but may not get the benefits of strategic trajectory planning and may get lower priority in dense traffic situations. Operators who prefer to self-separate can be accommodated whenever feasible, but may have to accept to be managed through certain airspace areas. The concept however depends upon operators to equip the majority of at least their new aircraft with trajectory exchange capabilities. Otherwise, the targeted benefits can likely not be achieved.

\section{Flight Operations of Conventional Aircraft}

Conventional aircraft will notice relatively little impact on their flight operations. FMS-equipped aircraft will be able to make more use of their FMS, thus increasing the flight efficiency. In low density airspace more direct routings and Continuous Descent Approaches (CDA) may be possible. In high density airspace however conventional aircraft will likely get lower priority than equipped aircraft.

Conventional aircraft equipped with airborne spacing capabilities can take advantage of enhanced sequencing and merging operations mostly in terminal areas. CPDLC for Transfer of Communication (TOC) and additional clearances may be used instead of voice communication.

\section{Flight Operations of Equipped Aircraft}

Equipped aircraft operations in CO-ATM managed airspace will be very different from today. The high flight path predictability should help schedule equipped aircraft reliably ahead of time and on short notice. Strategic trajectory changes can deliver aircraft on time along the most efficient routes. Low noise continuous descent approaches should be frequently facilitated. Runway spacing will be minimized with ASAS capabilities. Since every 
equipped aircraft provides a system wide benefit, additional incentives like scheduling and routing priorities could be put in place.

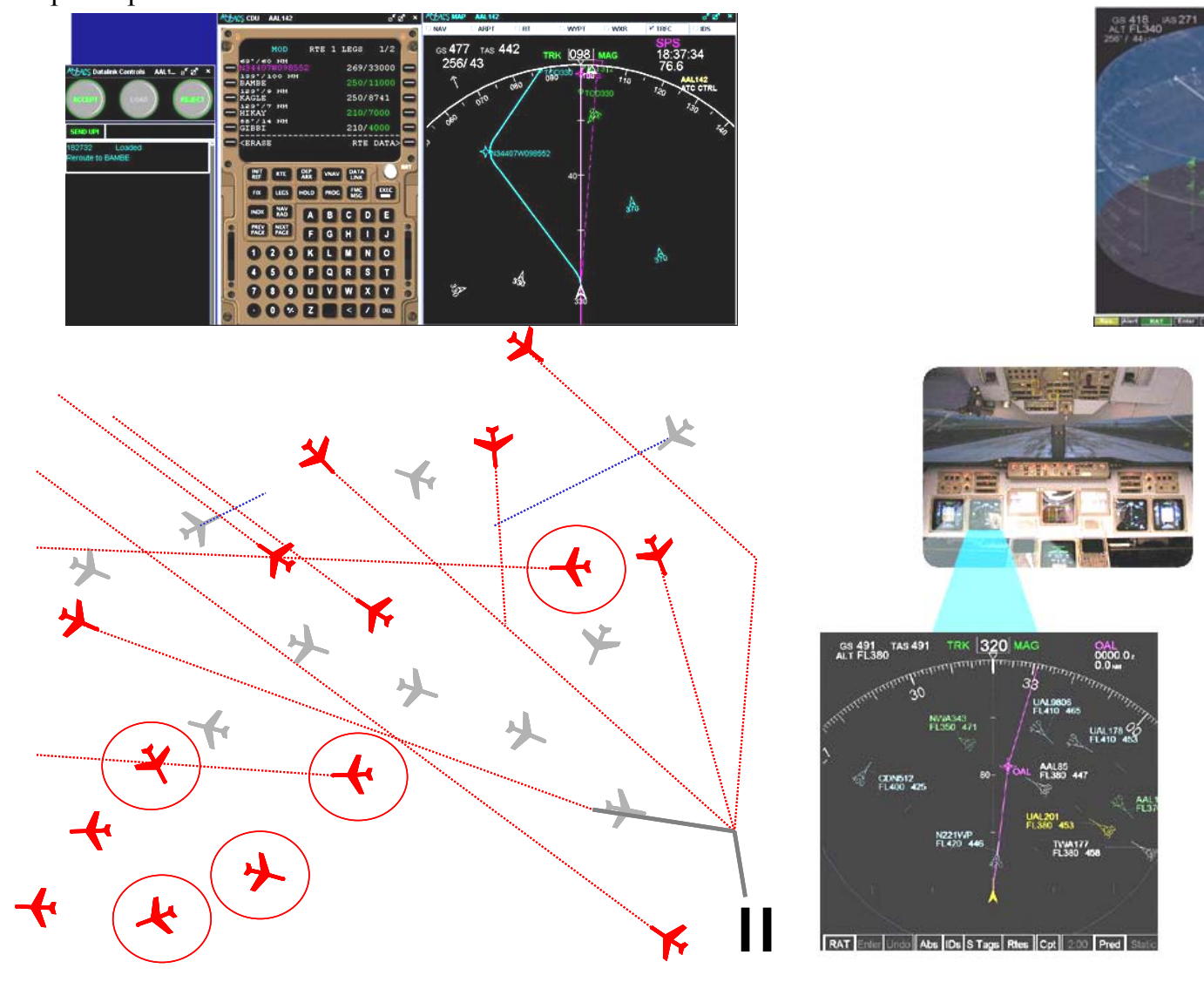

Figure 8: Conventional, and equipped aircraft share the same airspace, equipped aircraft require flight management systems with integrated data link. Self-separation may be possible depending on the traffic situation and requires additional airborne automation like a CDTI.

During flight operations, flight crews will experience little voice communication with controllers. Frequency changes will occur less frequently. Flight crews will fly coupled to their FMS at all times, except for short-term conflict avoidance. Flight crews may request preferred trajectories via data link or additional "maneuver room" for example for weather avoidance. Whenever a trajectory change is approved by the area controller/automation, flight crews are automatically cleared to follow this trajectory. A trajectory may include a time constraint that can be managed via climb/cruise/descent speed adjustments from the ground or via airborne required time of arrival functions. Flight crews may also be tasked with additional duties like sequencing and merging.

Airborne self-separation will be authorized by area controllers upon request whenever feasible. Reasons for prohibiting aircraft self-separation could be mixed equipage issues in the airspace, the flight crew intends to enter, and airspace or traffic flow requirements. In this case flight crews will continue to co-ordinate trajectory changes with the area controller/ground automation.

\section{E. Conflict Management}

Conflict management is an important issue in an environment with distributed separation responsibilities. The ground automation plays a primary role in conflict detection and resolution especially with regard to the area positions. The conflict detection process is aided by the availability of flight path intent for all aircraft in the ground system. This predictability is largely improved, if equipped aircraft transmit their intent information via data link, and if sector controllers use FMS compatible procedures and make the respective data entries into the ground system. An independent enhanced tactical conflict probe will be required to provide a safety net.

In addition to highly reliable automatic conflict probing, specific rules for conflict management and coordination will have to be defined. These rules should include: no near-term conflicts between conventional and equipped aircraft may be created by trajectory changes, and that all conflicts will have to be resolved within a 
certain time frame. Moreover, responsibilities for conflict resolution have to be clearly defined. However, since most area controllers and sector controllers can work in close proximity to each other and share a common air traffic picture, coordination between different positions should be possible building upon today's sector to sector coordination principles.

\section{Transition Approach}

The general transition approach proposed in this paper is the conceptual, procedural, and technological integration of ground-based and airborne capabilities - humans and automation - into one integrated air/ground system. This integrated air/ground system can build the foundation for any far-term air traffic system without requiring an upfront explicit definition of all of its final properties. During the transition process pilots and controllers can safely manage new tasks with gradual shifts in roles and responsibilities. The following transitions are fundamental to this approach:

- Transition from flight plan-based sector oriented air traffic control to 4D trajectory-based air traffic management

- Transition the controllers' role from issuing tactical instructions for a single sector by voice to an added role of managing strategic trajectory changes and various levels of aircraft autonomy for multiple sectors by CPDLC.

- Transition the flight crews' role from reacting to tactical controller instructions to actively participating in the trajectory and separation management tasks.

\section{A. Phasing in Area Positions and Data Link}

One of the intriguing properties of the CO-ATM concept is that it provides for a gradual transition path from today's environment to the target environment with increasing benefits. Sector controller operations and conventional aircraft operations will not experience any drastic changes immediately. The automation assisted, CPDLC integrated area position can be created as a new position. It might be beneficial to design the position as an extension to the current sector controllers' workstations. This reduces training and maintenance requirements and keeps the positions compatible. Controllers can initially monitor multi-sector operations and the automation behavior while separation responsibility stays with the sector controllers. Suggested trajectory adjustments can be coordinated with the sector controllers before data linking them to the aircraft. A number of aircraft have the required equipment or need only minor updates to be able to receive trajectory clearances.

When more trust has been gained, more equipage requirements are met, and the roles and responsibilities have been further defined, the responsibility for separating equipped aircraft can be assigned to the area positions. The number of aircraft controlled by the area position will increase with the number of equipped aircraft. It is expected that the first aircraft to equip will get early benefits, because the controller has more time available in assisting them. Furthermore, open issues can be addressed before the traffic volume increases. In the far-term it is expected that the sector controllers will handle less aircraft than the area controllers. The number of area flow controllers and sector controllers within a given airspace could be adjusted with the traffic volume. 
Table 2: Possible transition phases from the current system to a CO-ATM system.

\begin{tabular}{|c|c|c|c|c|}
\hline Current system & $\begin{array}{l}\text { Near-term transition } \\
\text { ( to 2012) }\end{array}$ & $\begin{array}{l}\text { Medium-term } \\
(2012-2020)\end{array}$ & CO-ATM 2025 & $\begin{array}{l}\text { Primary } \\
\text { Impact }\end{array}$ \\
\hline $\begin{array}{l}\text { Flight plan-based, } \\
\text { sector oriented. } \\
\text { Aircraft are } \\
\text { frequently vectored } \\
\text { off their flight plans, } \\
\text { flight information is } \\
\text { imprecise, passed } \\
\text { from sector to sector, }\end{array}$ & $\begin{array}{l}\text { Predict and distribute 4D } \\
\text { trajectories for all aircraft, } \\
\text { increase use of pre-defined } \\
\text { FMS routes and use ADS- } \\
\text { B-out to improve 4D } \\
\text { prediction accuracy, } \\
\text { increase use of time-based } \\
\text { TFM over miles-in-trail }\end{array}$ & $\begin{array}{l}\text { Integrate trajectory } \\
\text { downlink and other FMS } \\
\text { data to improve trajectory } \\
\text { prediction, communicate } \\
\text { STA's to aircraft. Enable } \\
\text { aircraft to manage to } \\
\text { RTA's if equipped }\end{array}$ & $\begin{array}{l}\text { 4D trajectory-based. Precise } \\
\text { 4D trajectories are shared } \\
\text { between flight deck, ATSP, } \\
\text { AOC and other potential } \\
\text { stakeholders Trajectories } \\
\text { from the aircraft are } \\
\text { compared to ground-based } \\
\text { expectations for } \\
\text { compliance, }\end{array}$ & $\begin{array}{l}\text { security, } \\
\text { predictability, } \\
\text { flexibility and } \\
\text { global inter - } \\
\text { operability } \\
\text { ATM }\end{array}$ \\
\hline $\begin{array}{l}\text { Sector controllers } \\
\text { issue tactical } \\
\text { instructions for } \\
\text { aircraft heading, } \\
\text { speed and altitude } \\
\text { changes in local } \\
\text { sectors }\end{array}$ & $\begin{array}{l}\text { Add procedures for sector } \\
\text { controller to issue FMS } \\
\text { compatible and ASAS } \\
\text { spacing clearances inside } \\
\text { sector, Add area flow } \\
\text { controllers with advanced } \\
\text { DSTs to coordinate } \\
\text { sequence, schedule and } \\
\text { FMS route changes with } \\
\text { sector controller and } \\
\text { AOC/TMU }\end{array}$ & $\begin{array}{l}\text { Integrate CPDLC with } \\
\text { DSTs on area positions, } \\
\text { increase authority of area } \\
\text { positions to data link } \\
\text { trajectory changes and } \\
\text { ASAS clearances directly } \\
\text { to aircraft. Automate sector } \\
\text { / multi-sector /TMU } \\
\text { coordination }\end{array}$ & $\begin{array}{l}\text { Area Flow Controllers } \\
\text { negotiate strategic trajectory } \\
\text { changes with pilots of most } \\
\text { aircraft and approve } \\
\text { /initiate/terminate increased } \\
\text { levels of aircraft autonomy } \\
\text { via CPDLC } \\
\text { Sector controllers control } \\
\text { less equipped aircraft and } \\
\text { handle local separation } \\
\text { problems if requested. }\end{array}$ & $\begin{array}{l}\text { Capacity, } \\
\text { efficiency, } \\
\text { environment } \\
\text { ATC }\end{array}$ \\
\hline $\begin{array}{l}\text { Flight crew reacts to } \\
\text { controller } \\
\text { instructions, has very } \\
\text { little traffic } \\
\text { awareness, rarely } \\
\text { uses FMS in } \\
\text { congested airspace }\end{array}$ & $\begin{array}{l}\text { Add FMS procedures to } \\
\text { make more use of FMS in } \\
\text { congested airspace, add } \\
\text { CDTI to create traffic } \\
\text { awareness, add airborne } \\
\text { spacing capabilities to } \\
\text { delegate limited ATC tasks } \\
\text { to flight crew. Receive } \\
\text { trajectory uplinks }\end{array}$ & $\begin{array}{l}\text { Integrate CPDLC with } \\
\text { FMS and CDTI, enable } \\
\text { trajectory requests from } \\
\text { the flight deck, increase } \\
\text { ASAS capabilities and } \\
\text { allow flight crew to } \\
\text { manage separation with } \\
\text { designated aircraft and/or } \\
\text { in designated low density } \\
\text { airspace }\end{array}$ & $\begin{array}{l}\text { Flight crew manages } \\
\text { coordinated or autonomous } \\
\text { operations, uses FMS } \\
\text { throughout the flight, is } \\
\text { aware of the surrounding } \\
\text { traffic, exchanges trajectory } \\
\text { modifications with area } \\
\text { controllers, chooses traffic } \\
\text { and weather optimal routes }\end{array}$ & $\begin{array}{l}\text { User preferences } \\
\text { All weather } \\
\text { operations, } \\
\text { Safety } \\
\text { Flight Crew }\end{array}$ \\
\hline
\end{tabular}

\section{B. Increasing Flight Deck Responsibility}

Airborne spacing is an initial step to delegate increased responsibility to the flight deck. Airborne spacing can be used as a tool for sector and area controller positions, because it does not require the same high equipage levels. Initial sequencing and merging applications enable controllers and flight crews to gain trust and experience in their new roles without changing responsibilities. Cockpit Displays of Traffic Information will provide increased situation awareness to the flight crews and may be used to make better informed trajectory requests that reflect the flight crew's preference and avoid conflict situations.

\section{Transition phases}

Table 2 summarizes potential transition steps for ATM, ATSP and flight crews from the current system to a COATM system. Obviously the transition will not occur in discrete steps or at the same pace in all areas. Therefore this table represents only one potential approach, indicating two phases: a procedural near-term transition phase and a technological medium-term phase. These two phases will be further investigated in our research on "Trajectory Oriented Operations with Limited Delegation (TOOWiLD)", starting with the near term phase.

\section{Future Research}

As mentioned, research at NASA Ames Research Center funded under NextNAS will further investigate transition phases towards CO-ATM. The research will be conducted with rapid prototyping methodologies and user involvement in simulations. Figure 9 depicts this iterative design process. 


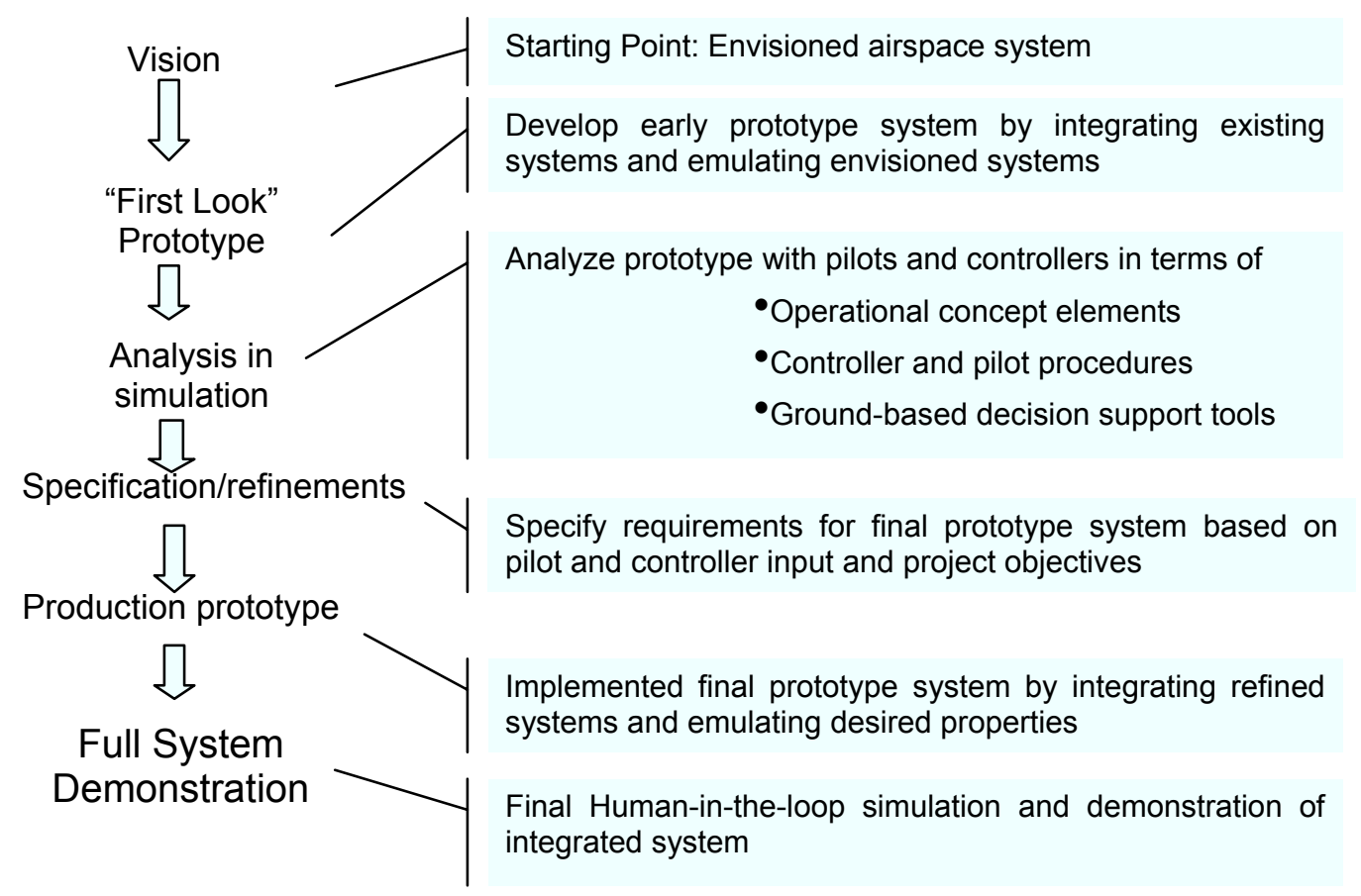

\section{Figure 9: Iterative Design Process}

The process focuses on the operational aspects of new concepts, the interactions of humans and humans, humans and automation, and automation and automation in a highly complex environment. It is aimed at evaluating feasibility, validating modeling assumptions, and specifying requirements on automation and procedures to enable the desired operations. The process enables rapid evaluation of the envisioned air traffic concept utilizing expert knowledge at critical stages.

As this paper indicates we are currently in the process of formulating the vision of CO-ATM - based on our experience and prior research. The vision is laid out in a concept definition describing the target system at a high level.

If the research goes into its next phase, the envisioned system is then turned into an early prototype by integrating simplified mock-ups of the primary new technologies into an emulation of the existing environment. This "first look" prototype provides an early reality check of concept feasibility and allows practitioners (i.e. pilots and controllers) to interact with the system in a "quasi" operational environment. It also provides an opportunity to demonstrate the system to all potential stakeholders. An early simulation analysis represents a possible decision point for either proceeding with the concept exploration as planned, redirecting its focus, or terminating this particular research at an early stage.

A simulation with pilots and controllers and other relevant parties such as airline dispatchers or air traffic managers is used to refine the concept and specify requirements for the mature system. The identified requirements are then turned into a revised prototype that integrates all relevant properties for evaluating the concept in a simulated operational target environment. This prototype is designed towards providing the desired look and feel to the operators and addressing all procedural issues. It is not intended to be an operational implementation of the automation. Thus, the software does not have to meet the high requirements imposed on operational systems and can be implemented in a straightforward and efficient manner.

The final human-in-the-loop evaluation is designed to measure whether the envisioned system meets the objectives targeted in the original concept definition. It also identifies the final specification for the required system components as well as subsystems that might be implemented in the near-term and could provide immediate benefits. In addition to the human-in-the-loop simulation fast time simulations and theoretical analyses need to be conducted to evaluate system-wide impacts. 


\section{Concluding Remarks}

New research has provided additional insights into the impact of different concepts on capacity, efficiency, and acceptability. The CO-ATM concept presented in this paper tries to leverage from the lessons learned from previous ATM research. CO-ATM represents a scalable framework for future air traffic operations and a transition path. More research and stakeholder involvement is required to prove the concepts effectiveness and affordability.

\section{Acknowledgments}

Trajectory-Oriented Operations with Limited Delegation (TOOWiLD) is funded under the Airspace Systems NextNAS project. DAG-TM research was funded by the Airspace Systems program as part of the Advanced Air Transportation Technologies Project (AATT). DAG-TM Simulation results used for this paper were generated with the help of many dedicated individuals at the AATT project office, the NASA Ames Flight Deck Display Research Laboratory, the NASA Ames Airspace Operations Laboratory, Crew Vehicle Systems Research Facility, and the NASA Langley Air Traffic Operations Laboratory. This work could not have taken place without the active support of the Air Line Pilots Association, the National Air Traffic Controllers Association, and the Air Traffic Services Office of the Federal Aviation Administration. The authors deeply appreciate their interest in and support of our research.

\section{References}

${ }^{1}$ Joint Planning and Development Office 2004, Next Generation Air Transportation System Integrated Plan. http://www.jpdo.aero

${ }^{2}$ FAA/Eurocontrol (2001) Action Plan 1 FAA/Eurcontrol Cooperative R\&D, Principles of Operation for the Use of Airborne Separation Assurance Systems Version 7.1, 19 June 2001

3 NASA, 1999, Concept Definition for Distributed Air/Ground Traffic Management (DAG-TM), http://www.asc.nasa.gov/aatt/dagconop.pdf

${ }^{4}$ Erzberger, H., 2004, Transforming the NAS: The Next Generation Air Traffic Control System, 24th International Congress of the Aeronautical Sciences, Yokohama, Japan, August 2005.

${ }^{5}$ Barhydt, R. and Kopardekar, P., submitted, Joint NASA Ames/Langley Experimental Evaluation of Integrated Air/Ground Operations for En Route Maneuvering, The Sixth International ATM R\&D Seminar ATM-2005, Baltimore, MD, July 2005.

${ }^{6}$ Lee P, Prevot T, Mercer J, Smith N and Palmer E, Ground-Side Perspective on Mixed Operations with Self-Separating and Controller-Managed Aircraft The Sixth International ATM R\&D Seminar ATM-2005, Baltimore, MD, July 2005.

${ }^{7}$ Smith, N., P. Lee, T. Prevôt, J. Mercer, E. Palmer, V. Battiste, and W. Johnson, 2004, A human-in-the-loop evaluation of air-ground trajectory negotiation, AIAA-2004-6260, American Institute of Aeronautics and Astronautics, Reston, VA.

${ }^{8}$ Callantine T., Lee P., Mercer J, Prevot T and Palmer E., . Air and Ground Simulation of Terminal Area FMS Arrivals with Airborne Spacing and Merging The Sixth International ATM R\&D Seminar ATM-2005, Baltimore, MD, July 2005.

${ }^{9}$ Barmore, B., T. Abbott, and K. Krishnamurthy, 2004, Airborne-managed spacing in multiple arrival streams, Proceedings of the $24^{\text {th }}$ International Congress of the Aeronautical Sciences, Yokohama, Japan.

${ }^{10}$ Grimauld I., Hoffmann E., Rognin L. and Zeghal K (2004) "Spacing instructions in approach: Benefits and limits from and air traffic controller perspective", AIAA 2004-5105, AIAA GNC conference, Providence, RI

${ }^{11}$ Eurocontrol (1999) PHARE ResearchProgramme. http://www.eurocontrol.int/phare

12 Callantine, T., Prevot, T., Smith, N., and Palmer, E. (2001). Simulation of CTAS/FMS Air Traffic Management. Proceedings of the 4th USA/Europe Air Traffic Management Research and Development Seminar, Air-Ground Cooperation Track, Santa Fe, NM

${ }^{13}$ Crane, B, T. Prevot and E. Palmer. (1999) Flight Crew Factors for CTAS/FMS Integration in the Terminal Airspace. NASA Technical Memorandum 2000-209607, NASA Ames Research Center, Moffett Field, CA.

${ }^{14}$ Green, S.M. and R. Vivona, 1996, Field Evaluation of Descent Advisor Trajectory Prediction Accuracy, AIAA 96-3764, AIAA Guidance, Navigation, and Control Conference, July.

${ }^{15}$ Williams, D.H. and S.M. Green, Flight Evaluation of Center-TRACON Automation System Trajectory Prediction Process, NASA/TP-1998-208439, July, 1998.

${ }^{16}$ Prevot T., P. Lee, T. Callantine, N. Smith, and E. Palmer (2003a) Trajectory-Oriented Time-Based Arrival Operations: Results and Recommendations, ATM2003, FAA/Eurocontrol R\&D Seminar, Budapest, Hungary

${ }^{17}$ Lee P., J. Mercer, T. Prevot, N. Smith, V. Battiste W. Johnson R. Mogford, and E. Palmer, 2003, Free Maneuvering, Trajectory Negotiation, and Self-Spacing Concepts in Distributed Air-Ground Traffic Management, ATM2003, FAA/Eurocontrol R\&D Seminar, Budapest, Hungary.

${ }^{18}$ Prevot, T., Callantine T, Kopardekar P, Smith N, Palmer E and V Battiste (2004) Trajectory-Oriented Operations with Limited Delegation: An Evolutionary Path to NAS Modernization. AIAA $4^{\text {th }}$ ATIO Forum, AIAA-2004-6449

${ }^{19}$ Prevot T., Lee P, Smith, N. and Palmer E. (2005), ATC Technologies for Controller-Managed and Autonomous Flight Operations. AIAA Guidance Navigation and Control Conference, San Francisco, CA 2005

${ }^{20}$ Prevot T. (2005) On the Design of Integrated Air/Ground Automation. IEEE SMC 2005, Hawaii, HI, October 2005 
${ }^{21}$ Boeing et al. (2005) “Tailored Arrivals" e.g. http://www.boeing.com/news/releases/2005/q1/nr_050131a.html and http://usrwww.mpx.com.au/ cjr/Tap\%20Report.htm

22 Johnson, W., Battiste V., and Bochow S. (1999): A cockpit display designed to enable limited flight deck separation responsibility, SAE Technical Paper 1999-01-5567, SAE International, Warrendale, PA

${ }^{23}$ Graham, R., E. Hoffmann, C. Pusch, and K. Zeghal, (2002, 2003) "Absolute versus Relative Navigation: Theoretical Considerations from an ATM Perspective", ATM2003, FAA/Eurocontrol R\&D Seminar, Budapest, Hungary

${ }^{24}$ Prevot, T., Shelden, S., Mercer, J., Kopardekar, P., Palmer, E., and Battiste, V. (2003): "ATM concept integrating trajectory-orientation and airborne separation assistance in the presence of time-based traffic flow management". Proceedings of the 22nd DASC, AIAA-2003-197. Indianapolis, IN.

25 Prevot T., Battiste V., Callantine T. Kopardekar P., Lee P., Mercer J., Palmer E., Smith N. (2005) Integrated Air/Ground System: Trajectory-Oriented Air Traffic operations, Data Link Communication, and Airborne Separation Assistance" Air Traffic Control Quarterly Volume 13, Number 2 Special Issue on ASAS, pp. 201-229, (Francis Casaux Editor) 